\title{
Harmonic Contributions of Utility and Customer Based on Load Model Using Field Measurements
}

\author{
Ömer Gül, Tayfun Gündoğdu \\ Department of Electrical Engineering, Istanbul Technical University, Istanbul, Turkey \\ Email: gulomer@itu.edu.tr, tgundogdu@itu.edu.tr
}

Received 19 March 2015; accepted 29 April 2015; published 5 May 2015

Copyright (C) 2015 by authors and Scientific Research Publishing Inc.

This work is licensed under the Creative Commons Attribution International License (CC BY). http://creativecommons.org/licenses/by/4.0/

(c) (i) Open Access

\begin{abstract}
In recent years, sinusoidal waveform of the current and voltage disturbs in the electrical distribution system because of the due to the increasing number of non-linear loads. Many standards of IEC and IEEE standards have been published in order to limit the voltage and current waveform distortion. The operators of the electricity distribution network widely use the power quality monitoring systems at the point of common connection (PCC). It has been identified that there are substantial number of harmonic currents excess of the standards transferred to the grid according to the data obtained from power quality monitoring systems. In case of exceeding the limits specified in the standards, there is a need to determine the network and customer responsibilities for the implementation of required sanctions. In this study, using recorded data at the PCC of a medium voltage electrical distribution system, voltage and current harmonic distortion responsibilities of the network and customer are determined by the improved harmonic current vector method. Up-to-date load model based on field measurement which provides more accurate results has been used instead of the constant load impedance in the proposed method.
\end{abstract}

\section{Keywords}

Harmonic Contributions, Harmonic Distortion Load Model, Norton Equivalent

\section{Introduction}

In addition to the known harmonics sources, the wide spread use of power electronic devices cause to injection of more harmonic currents in the electrical distribution network. Therefore, voltage waveform distortion is increasing with each passing day. Consisting harmonic currents as a result of connecting of a non-linear load to 
the network causes the network's voltage to become harmonic as a result of the harmonic voltage drop at the network impedance. In this case, even if the linear load is connected to the network, harmonic currents will continue to flow reference measurement point [1]. To avoid an increase in waveform distortion of the electricity distribution network, some harmonic currents restrictions have been imposed on the production stage of the electrical devices according to standards.

In case of to be exceeded of the limit values which are determined by the standards, it is required to take precautions in order to reduce the waveform distortion. Some responsibilities in the distortion of the waveform should be determined to realize who is responsible for this distortion. The source side of the PCC is under the network responsibility while the load side of the PCC is under the customer responsibility. Therefore, the field measurements are of great importance for determining the responsibilities of the customer or/and the network. In the case of the determination of responsibilities, it will be able to punish to customer and/or the network according to their responsibility rate at the PCC.

The harmonic analysis studies of three-phase power distribution networks, modeling of loads [2]-[8], and the identification of customer contributions [9] are still up-to-date. Efforts to seek solutions for harmonics injected by the nonlinear load and under the condition of the load is not fully specified have begun a few decades ago [10]. A virtual instrument dedicated for the analysis of power signals, in order to determine the existence and characteristics of harmonic distortion is proposed. The processing algorithm are based on estimate harmonic emission level and obtain the real-time estimates of regression coefficients, and then calculate the level of the harmonic impedance and emission estimates in real time [11].

In a study using the value of the reference impedance, changes in the harmonic sources are included by converting the impedance changes into equivalent current sources [9]. The method of harmonic current vector, which shows the network and customer as their Norton equivalent, seems to be theoretically correct [10]. Harmonics caused by the customer and network are calculated by using this method. The most important shortcoming of this method is that it requires knowledge of customer and consumer impedances. The load impedance varies quite a lot according to the network impedance. Therefore, it is not clear how to use reference impedance approach for the loads [10]. One other study clarifies the harmonic current vector method to determine the reference impedance. By selection of load resistance as reference impedance calculations are not affected under the resonance situation [12]. Reactive power flow direction at PCC has been based on by another study [14]. Many methods have been applied in order to keep the harmonic distributions within certain limits between the client and distribution network. Since the measurements taken from different points in a network at the same time is quite difficult and expensive [14]-[18], to be able to perform the measurements at the PCC more practical approaches should be developed [19]. Despite using various measurement methods in the determination of the total harmonic distribution at the PCC, none of them is practical. Power flow direction method, which is a well-known method [20], has been considered as not a feasible method in the determination of the harmonic source [21]. Several different electrical quantities have been discussed as a criterion for harmonic cost distortion, however, only estimated harmonic cost distortion could be calculated [22].

Harmonic Current Method, which is modeled by Norton equivalent circuit of the customer and the network for a specific harmonic degree, is considered theoretically correct, although it shows some practical shortcomings [12]. This method does not take into account any resonance condition; it just requires knowledge of impedance of the customer and the network at any harmonic degree. Reference impedance methods were found in order to determine the customer and the network impedances, but the studies are still continuing [12].

While the load impedance is constantly changing, to use the reference impedance method which assumes the load impedance as constant does not provide sufficiently accurate results. Because, switching positions of the filter and compensation capacitors can cause very large changes in the load impedance. Instead of the reference impedance method, use of harmonic current method with the approach to updating the load impedances online by using the field measurements will provide more accurate results. Furthermore, switching positions of the filters and capacitors have been already taken in to account in the proposed algorithm by means of the long-term measurements at the PCC.

This study proposes a new method, which is based on measurement of current and voltage at the PCC, in order to determine the responsibilities of the network and costumer. Moreover, it is provided that the current vector method has been improvement by using constantly changing impedance. In the proposed method, up-to-date load model based on field measurement has been used instead of the constant load impedance.

In order to determine the current and voltage contributions to the PCC, Norton and Thevenin equivalent circuits of the network and costumer have been used with an algorithm. The proposed algorithm is verified in 
MATLAB by processing of the measurements. After the processing of the data collected from the PCC for a long-time period, the responsibility of the customer and the network at the PCC and current and voltage THD values have been obtained.

\section{Harmonic Vector Method with Reference Impedance}

Impedance of the customer and the network are of great importance in determining the compliance of the harmonic standards. The contract between the customer and the network is determined by value of the reference impedance [15]. Usually, the reference impedance value is not exactly equal to the actual value of the impedance. These reference impedance values are taken as basis in determining whether the customer violates or not the harmonic limits.

Harmonic Vector Method is the representation of the circuit of the customer and network sides with Thevenin/Norton equivalent circuits. Harmonic current or voltage at the PCC are separated into two components (customer and network) in order to identify the individual harmonic distribution. The equivalent circuit is composed as $h$ order harmonic current or voltage source for both customer and network circuits.

Although, characteristics of the customer impedance and especially frequency are known rarely, the impedance of the network side is usually particular. Active harmonic impedance of the customer side is very difficult to determine due to the constantly changing characteristics of the customer side. Therefore, equivalent impedances are determined as reference impedance. The main idea is to describe either the customer or the network side impedances as a reference to an additional source of harmonic. In general, resistive component of the customer side is determined as customer reference impedance. This situation depends on the distribution of the current or voltage harmonics [23].

\section{Harmonic Voltage Contributions}

To determine the contribution of the harmonic voltage, the Thevenin equivalent circuit shown in Figure 1 is used. This equivalent circuit consists of network $\left(U_{U h}\right)$ and customer $\left(U_{C h}\right)$ voltage source, and network $\left(Z_{U h-\text { ref }}\right)$ and customer $\left(Z_{C h-\text { ref }}\right)$ reference impedance which include $h$ order harmonic.

As can be seen in Figure 2 where $R_{C l s}$ is the customer reference impedance, an additional reactance voltage drop is converted to a harmonic source. Customer reference impedance is modeled by a resistor and reactance which are connected in series as seen in Figure 2.

$$
\begin{aligned}
& Z_{C h-\text { ref }}^{*}=R_{C l s}=\frac{P}{\left|I_{P 1}\right|^{2}}=\frac{\left|U_{P 1}\right| \cdot \cos \phi_{P 1}}{\left|I_{P 1}\right|} \\
& U_{C h}=U_{P h}-I_{P h} \cdot R_{C l s} \\
& U_{U h}=U_{P h}+I_{P h} \cdot Z_{U h-\text { ref }}
\end{aligned}
$$

The customer reference impedance is calculated as Equation (1) using the active power $P$ measured at connection point and current at the fundamental frequency $I_{P 1}$. Where, $\phi_{P 1}$ is the phase angle between the current

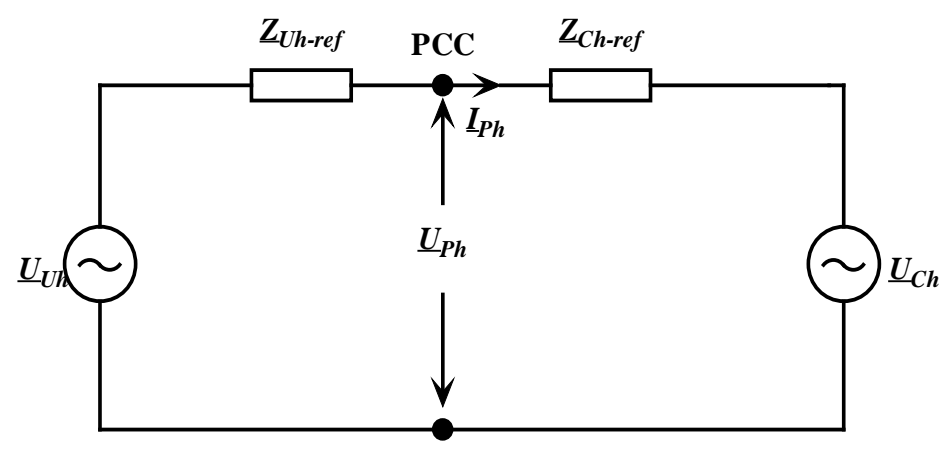

Figure 1. Thevenin equivalent circuit of network and customer at any order of the harmonic. 
and voltage at the fundamental frequency. Customer harmonic voltage $\left(U_{C h}\right)$ and network harmonic voltage $\left(U_{U h}\right)$ are obtained from the Equations (2) and (3) according to Figure 3.

Generally, customers are connected to the network via transformer. So, reference impedance of the network is determined as the sum of the impedance of the last transformer before connected to the customer and the short-circuit impedance of the network. This impedance composes the basic part of the network impedance and value of this impedance can be found easily. However, networks should provide an impedance close to the current impedance and should avoid from the unnecessary impedances which cause the harmonic distortion.

Additives to voltage value at the customer and network connection point are given Equations (4) and (5) applying the superposition principle as shown in Figure 3.

$$
\begin{aligned}
& \underline{U}_{U-P h}=\frac{R_{C l s}}{\underline{Z}_{U h-\text { ref }}+R_{C l s}} \cdot \underline{U}_{U h} \\
& \underline{U}_{C-P h}=\frac{\underline{Z}_{U h-\text { ref }}}{\underline{Z}_{U h-\text { ref }}+R_{C l s}} \cdot \underline{U}_{C h}
\end{aligned}
$$

Harmonic voltage phasor measured at the connection point $\left(U_{P h}\right)$, is the vectoral summation of the harmonic voltage contributions of the customer and network. Taking account the projection of contribution of the network voltage $\left(U_{U-P h}\right)$ and customer voltage $\left(U_{C-P h}\right)$ to the measured voltage of the connection point $\left(U_{P h}\right)$, scalar network voltage harmonic contribution $\left(U_{U h s}\right)$ and customer scalar harmonic contribution $\left(U_{C h s}\right)$ are calculated as Equations (6) and (7).

$$
\begin{aligned}
& U_{U h s}=\left|\underline{U}_{U-P h}\right| \cdot \cos \left(\delta_{U-P h}-\delta_{P h}\right) \\
& U_{C h s}=\left|\underline{U}_{C-P h}\right| \cdot \cos \left(\delta_{C-P h}-\delta_{P h}\right)
\end{aligned}
$$

where, $\delta_{U-P h}$ is angle between contribution of the network harmonic voltage and connection point voltage, and $\delta_{C-P h}$ is the angle between contribution of the customer harmonic voltage and connection point voltage. Total harmonic voltage of the connection point is equal to sum of the scalar harmonic components of the network and the customer. This scalar quantities can be positive or negative values, and thus current can increase or decrease at the PCC.

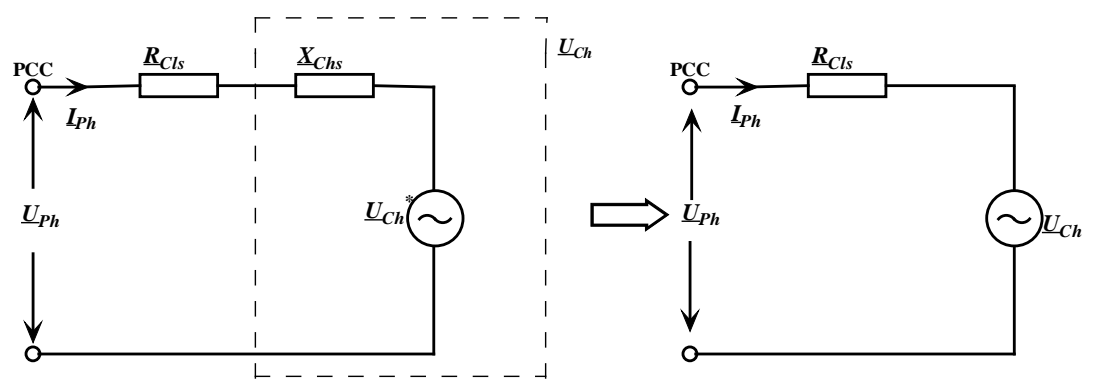

Figure 2. Conversion of reactance voltage drop to an additional source.
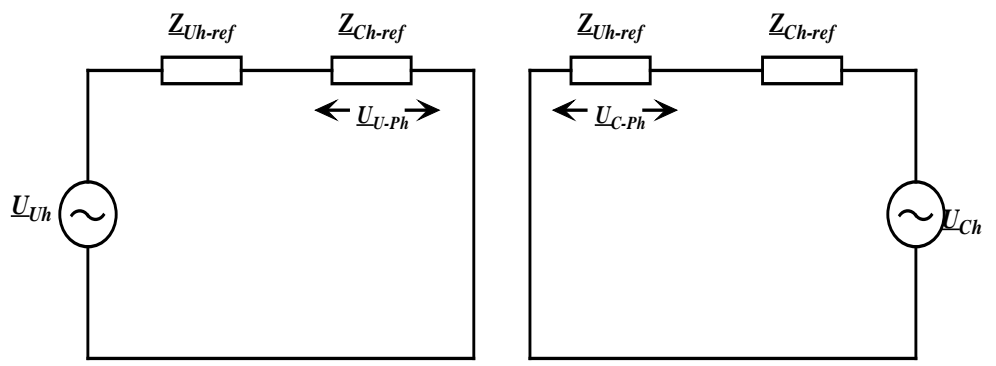

Figure 3. Implementation of superposition principle for the detection of customer and network voltage harmonics. 


\section{Harmonic Current Contributions}

Resonance between the load and the network status is a common occurrence. Limits defined in the standards are usually exceeded due to the increasing harmonic distortion in case of resonance. Responsibilities should be determined in order to put leverage on the customer and network sides when the limits are exceeded. Norton equivalent circuit in which network and customer reference impedances are used shown in Figure 4 . Where $I_{U h}$ and $Z_{U h-r e f}$ indicate the network harmonic current and reference impedance at the $h$. harmonic order, respectively, and $I_{C h}$ and $Z_{C h \text {-ref }}$ indicate the customer harmonic current and reference impedance at the $h$. harmonic order, respectively.

Reference impedance calculation is quite difficult due to the continuously changing state of the load. Reference impedances may be determined due to the measured values at the reference connection point (PCC) according to the general impressions among the researchers. Reference impedance of the network is the sum of the short-circuit impedances and the impedance of the first transformer before the customer connection point. Resistive part of the load impedance of the customer $\left(R_{C l p}\right)$ may be found by the measurements at the connection point. Customer impedance can be expressed by a resistance and an impedance parallely connected while dealing with the calculations of the harmonic current contributions.

Customer impedance can be calculated as in Equation (8) by using the active power $(P)$ and basic component of the voltage $\left(U_{P 1}\right)$ in absence of customer side of active load production.

$$
Z_{C h \text {-ref }}=R_{C l p}=\frac{\left|U_{P 1}\right|^{2}}{P}=\frac{\left|U_{P 1}\right|}{\left|I_{P 1}\right| \cdot \cos \phi_{P 1}}
$$

In the Equation (8), is the angle between measured current and voltage at the fundamental frequency, and $\left|U_{P 1}\right|$ and $\left|I_{P 1}\right|$ are the voltage and current magnitudes are the fundamental frequency. Customer and network harmonic currents are obtained by Equations (9) and (10) according to Figure 5.

$$
\begin{gathered}
I_{C h}=\frac{\underline{U}_{P h}}{\underline{R}_{C l p}}-I_{P h} \\
I_{U h}=\frac{\underline{U}_{P h}}{\underline{Z}_{U h-\text { ref }}}+I_{P h}
\end{gathered}
$$

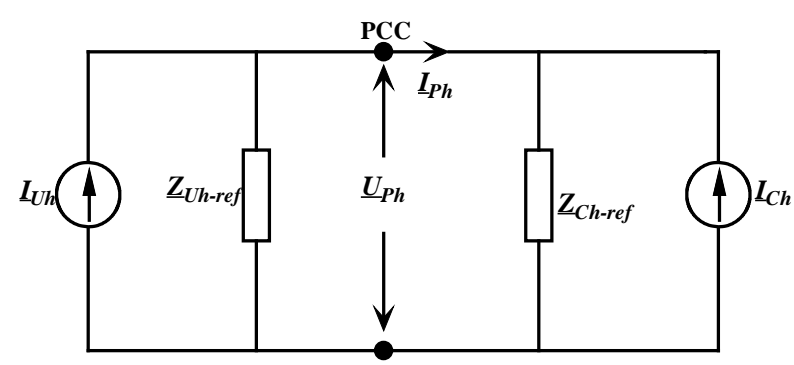

Figure 4. Norton equivalent circuit for the analysis of harmonic current in a specific-grade.
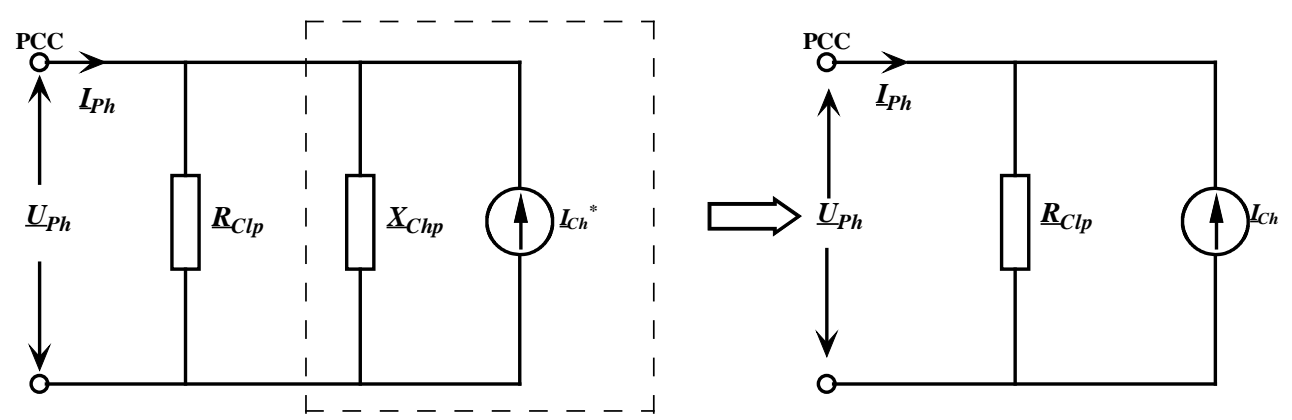

Figure 5. Transformation of the reactance current to an additional harmonic current source. 
Harmonic current contributions of the network and customer to the $I_{P h}$ connection point are determined by principle of Superposition. Customer and network harmonic current contributions are determined by using Equations (11) and (12) according to Figure 6.

$$
\begin{aligned}
& \underline{I}_{U-P h}=\frac{\underline{Z}_{U h-\mathrm{ref}}}{\underline{Z}_{U h-\mathrm{ref}}+R_{C l p}} \cdot \underline{I}_{U h} \\
& I_{U h}=\frac{\underline{U}_{P h}}{\underline{Z}_{U h-\mathrm{ref}}}+I_{P h}
\end{aligned}
$$

Total Harmonic current $\left(I_{P h}\right)$ at the connection point can be separated into two scalar components as seen in Figure 7.

Scalar harmonic contributions of the Customer and Network are calculated as in Equations (13) and (14) by using harmonic currents of customer $\left(I_{C-P h}\right)$ and network $\left(I_{U-P h}\right)$ using the projection of these currents to total harmonic current $\left(I_{P h}\right)$.

$$
\begin{aligned}
& I_{U h s}=\left|\underline{I}_{U-P h}\right| \cdot \cos \left(\phi_{U-P h}-\phi_{P h}\right) \\
& I_{C h s}=\left|\underline{I}_{C-P h}\right| \cdot \cos \left(\phi_{C-P h}-\phi_{P h}\right)
\end{aligned}
$$

where, $\phi_{U-P h}$ is the phase angle between the $I_{U-P h}$ and $I_{P h}$, and $\phi_{C-P h}$ is the phase angle between the $I_{C-P h}$ and $I_{P h}$. As seen in Figure 7, $I_{P h}$ is equal to sum of the scalar harmonic current of the network $\left(I_{U h s}\right)$ and customer $\left(I_{C h s}\right)$. If there any negative signed component in the summation, it compensates a specific-grade positive signed component and reduces the amplitude of related harmonic.

\section{Load Model Using Field Measurements}

A distribution system comprises a number of loads conveniently supplied by circuits from the nearest distribution point. The distribution circuits' configuration depends on the particular load requirements. A considerable number of loads (linear or nonlinear) are located so close together and supplied from the main distribution point, that they can be considered as whole. The aggregate form of various individual loads called general loads. Residential and commercial buildings can be called as general loads since they have a number of linear and nonlinear load combinations rated at low power values. Owing to the fact that some of the loads in buildings switch on and switch off continuously, the buildings as a general load have varying characteristics and mostly operate unbalanced. Moreover, due to harmonic currents drawn by nonlinear loads, the waveform of voltage in the



Figure 6. Determination of harmonic current contributions by principle of Superposition.

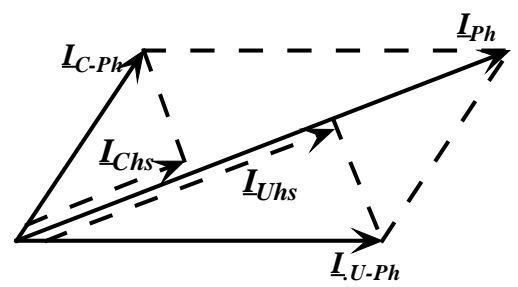

Figure 7. Harmonic current contributions of the customer and network to the harmonic current of the connection point. 
buildings becomes distorted. It is therefore that the buildings are very sophisticated loads in terms of modeling. Consequently, using the measured voltage and current data to model these types of loads can be an alternative solution.

The generalized time domain load model is based on actual recorded data and is an extension of the ideas proposed in [24]. The total load current $\left(i_{T}(t)\right)$ is split into components that are orthogonal to the voltage. That part of the total current that corresponds to uncommon harmonics with the voltage is called the generated component $\left(i_{g}\right)$ [18]. The current $\left(i_{p}\right)$ is the component in phase with the source voltage and is modeled as the current through a resistor. The quadrature component of the current $\left(i_{q}\right)$ given in (15) is split up into an inductive reactive component $\left(i_{l}\right)$, a capacitive reactive component $\left(i_{c}\right)$, and a residual component $\left(i_{r}\right)$. The component $\left(i_{g}\right)$ exists only when there are uncommon harmonics between the load voltage and the current. The residual component $i_{r}(t)$ exists when complete extraction of orthogonal components cannot be done. This component is orthogonal to the voltage and is shown in Figure $\mathbf{8}$ as the current flowing through a "Black Box". For load modeling applications however, this "Black Box" may be replaced by a current source of appropriate magnitude and phase angle at each common harmonic frequency or as an equivalent impedance at each harmonic frequency.

$$
i_{q}(t)=i_{T}(t)-i_{g}(t)-i_{p}(t)=i_{c}(t)+i_{l}(t)+i_{r}(t)
$$

Given the measured voltage $v(t)$ and current $i_{T}(t)$ as

$$
\begin{aligned}
& v(t)=\sqrt{2} \sum_{n=1}^{N} V_{n} \cos \left(n \omega t+\alpha_{n}\right), \\
& i_{T}(t)=\sqrt{2} \sum_{n=1}^{M} I_{n} \cos \left(n \omega t+\beta_{n}\right) .
\end{aligned}
$$

where $N$ and $M$ are the number of harmonics in the voltage and current respectively. $V_{n}$ and $I_{n}$ represent the RMS values of the $n^{\text {th }}$ harmonic voltage and current respectively. $\alpha_{n}$ and $\beta_{n}$ represent the phase angles of the $n^{\text {th }}$ harmonic voltage and current respectively. The load parameters $R, L$, and $C$ are calculated based on the voltage $V(t)$ and current $i(t)$ as follows:

$$
R=\frac{(v(t))^{2}}{\frac{1}{T} \int_{0}^{T} v(t) \cdot i(t) \mathrm{d} t}, \quad L=\frac{\frac{1}{T} \int_{0}^{T}(w(t))^{2} \mathrm{~d} t}{\frac{1}{T} \int_{0}^{T} i(t) \cdot w(t) \mathrm{d} t}, \quad C=\frac{\frac{1}{T} \int_{0}^{T} i(t) \cdot \frac{\mathrm{d} v(t)}{\mathrm{d} t} \mathrm{~d} t}{\frac{1}{T} \int_{0}^{T}\left(\frac{\mathrm{d} v(t)}{\mathrm{d} t}\right)^{2} \mathrm{~d} t}
$$

where $T$ denotes the period, $w(t)$ is defined as the alternating part of $\int_{0}^{T} v(t) \mathrm{d} t$. In the calculation of the required costumer parameters, mentioned load model has been used. And the calculated parameters are given in Section 5.

\section{Proposed Harmonic Contribution Method}

In order to determine the responsibilities of the network and costumer, real impedance value of the customer which is calculated by measuring current and voltage at the PCC has been used in proposed model instead of the constant load impedance. To be able to use the proposed method, equivalent model of the grid system should be

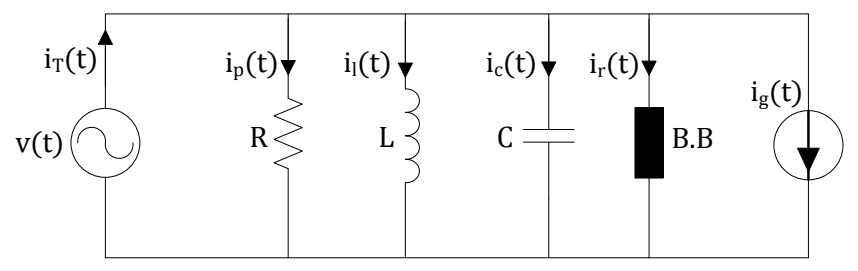

Figure 8. General equivalent network and current components. 
prepared after the measurements at the PCC. After the establishment of Norton and Thevenin equivalent, contributions at the PCC can be found precisely.

In this study, superposition method is applied to the equivalent circuit of this grid system by using MATLAB after modeling of a real grid system. Norton equivalent circuit is used for harmonic current contributions while Thevenin equivalent circuit is used for harmonic voltage contributions. It is very important to determine the network and customer sides in a real grid system. Actually, there are lots of customers connected in parallel to each other on a real grid system. In Figure 9 it shown that from where the field measurements should be performed in the case of there are multiple customer on the system.

MATLAB program has been prepared to calculate the fundamental, $5^{\text {th }}, 7^{\text {th }}, 11^{\text {th }}, 13^{\text {th }}$ and $17^{\text {th }}$ harmonic levels of the current and voltage of customer and network sides, individually. Harmonics that are the $3^{\text {th }}$ and multiples of three and that are not found on symmetrical and balanced systems are not taken into account. The circuit, whose field measurements are performed, has been modelled as given in Figure 10.

Decomposition of the network and customer current and the voltage are done at the PCC by using Figure 11 and Figure 12. In order to determine percentage of the contributions of the network and customer currents at the PCC, Equation (18) is used. $I_{r}(t)$ and $I_{g}(t)$ are modeled as a single current source $\left(I_{C}\right)$, and RLC are modeled as a single impedance $\left(Z_{C}\right)$ at the customer side of the grid model as shown in Figure 11 and Figure 12. Load impedance has been updated with repeated measurements.

$$
\begin{aligned}
& I_{u}=\frac{V_{\mathrm{pcc}}}{Z_{u}}+I_{\mathrm{pcc}}, \quad I_{c}=\frac{V_{\mathrm{pcc}}}{Z_{c}}-I_{\mathrm{pcc}}, \\
& I_{u \mathrm{pcc}}=\frac{Z_{u}}{Z_{c}+Z_{u}} I_{u}, \quad I_{c \mathrm{ccc}}=\frac{Z_{c}}{Z_{c}+Z_{u}} I_{c} .
\end{aligned}
$$

where, $I_{\text {upcc }}$ indicates the contribution of the PCC current to the network current and $I_{\text {cpcc }}$ indicates the contribution of the PCC current to the customer current. $I_{u}$ and $I_{c}$ indicate the modelled currents of the network



Figure 9. View of the PCC and determination of the grid according to customers.

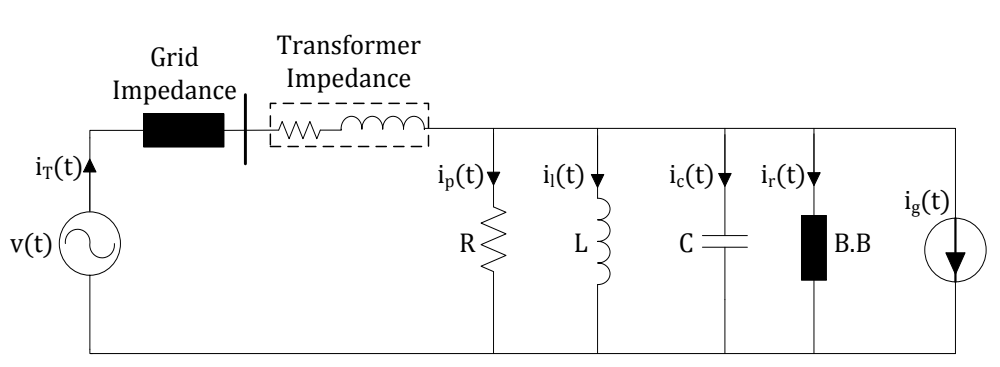

Figure 10. Model of customer and network. 
and customer, respectively. The accuracy of the calculated network and customer currents can be proven with the condition of being equal to each other of the result of Equation (19) and measured value of the PCC current [9] [14].

$$
\left|I_{\mathrm{pcc}}\right|=I_{\text {upcc }}+\left(-I_{\mathrm{cpcc}}\right)
$$

In order to realize the contribution of the network and customer voltages to the voltage of PCC in what rate Equation (20) is used.

$$
V_{\text {upcc }}=\frac{Z_{u} * Z_{c}}{Z_{u}+Z_{c}} I_{u}, \quad V_{\text {срсc }}=\frac{Z_{u} * Z_{c}}{Z_{u}+Z_{c}} I_{c}
$$

where, $V_{u p c c}$ indicates the contribution of the PCC current to the network voltage and $V_{\text {cpcc }}$ indicates the contribution of the PCC current to the customer voltage. The accuracy of the calculated network and customer voltages can be proven with the condition of being equal to each other of the result of Equation (21) and measured value of the PCC voltage [9] [13].

$$
\left|V_{\mathrm{pcc}}\right|=V_{u \mathrm{pcc}}+V_{\text {cрсc }}
$$

\section{Results of the Proposed Method with Field Measurements}

One-line diagram of the test system where the measurements were recorded with permission of the Bosporus Electricity Distribution company (BEDAŞ) is shown in Figure 13. As seen in one-line diagram of the test system, there is only one customer connected to the network. Analyzed energy system given in Figure 13 has (2.5 $+12 \mathrm{i}) \mathrm{m} \Omega$ grid impedance and $(42.5+108.75 \mathrm{i}) \mathrm{m} \Omega$ transformer impedance per phase.

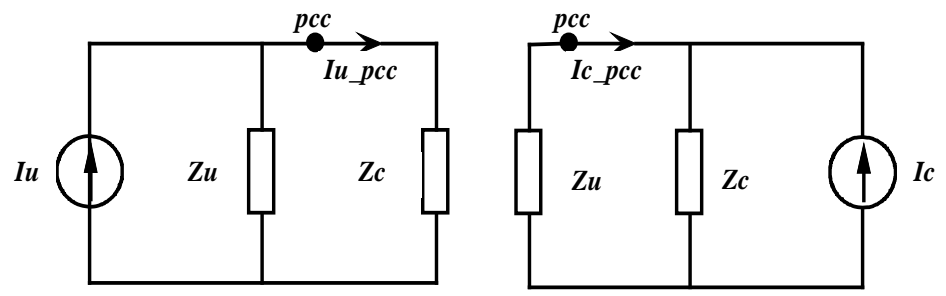

Figure 11. Modelled Norton equivalent circuit for the determination of currents on the PCC.
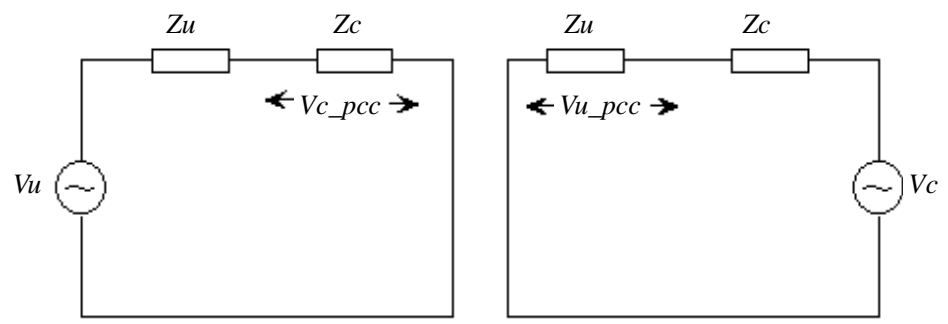

Figure 12. Modelled Thevenin equivalent circuit for the determination of voltages on the PCC.

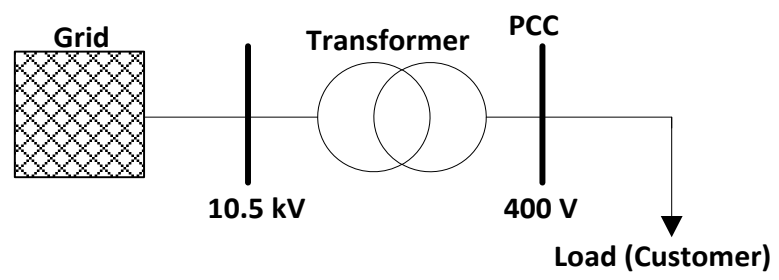

Figure 13. One-line diagram of the test system. 
Load model were determined with the field measurements. Measurements had been taken and recorded during the 40 hours in order to determine the contributions of the network and customer current and voltage to the PCC. Sampling time of the measurement is 5 minutes. Instant measurement taken from the PCC were processed via MATLAB according to method described Section 3. According to this method the customer load impedance varies between $(0.14+0.1 \mathrm{i}) \Omega$ and $(0.6+1.1 \mathrm{i}) \Omega$.

As a result of processing of the measurement data at the PCC shown in Figure 13 voltage and currents contributions of the network and customer to the PCC at the fundamental frequency are shown in Figure 14 and Figure 15. The indices " $c$ ", " $u$ " and "pcc" used the graphics indicate costumer, utility (network), and point of common coupling, respectively. As shown in the Figure 14 and Figure 15, power drawn from the network varies according to the time.

After the measurements of the current and voltage, load impedance was calculated by using (8) and given in Figure 16. As seen in the Figure 16, magnitude of the load impedance varies between $0.172 \Omega$ and $1.25 \Omega$ with time. Even if the type of the load does not known specifically, their affect to the total load impedance have already been taken into account by means of the constantly updated voltage and current data.

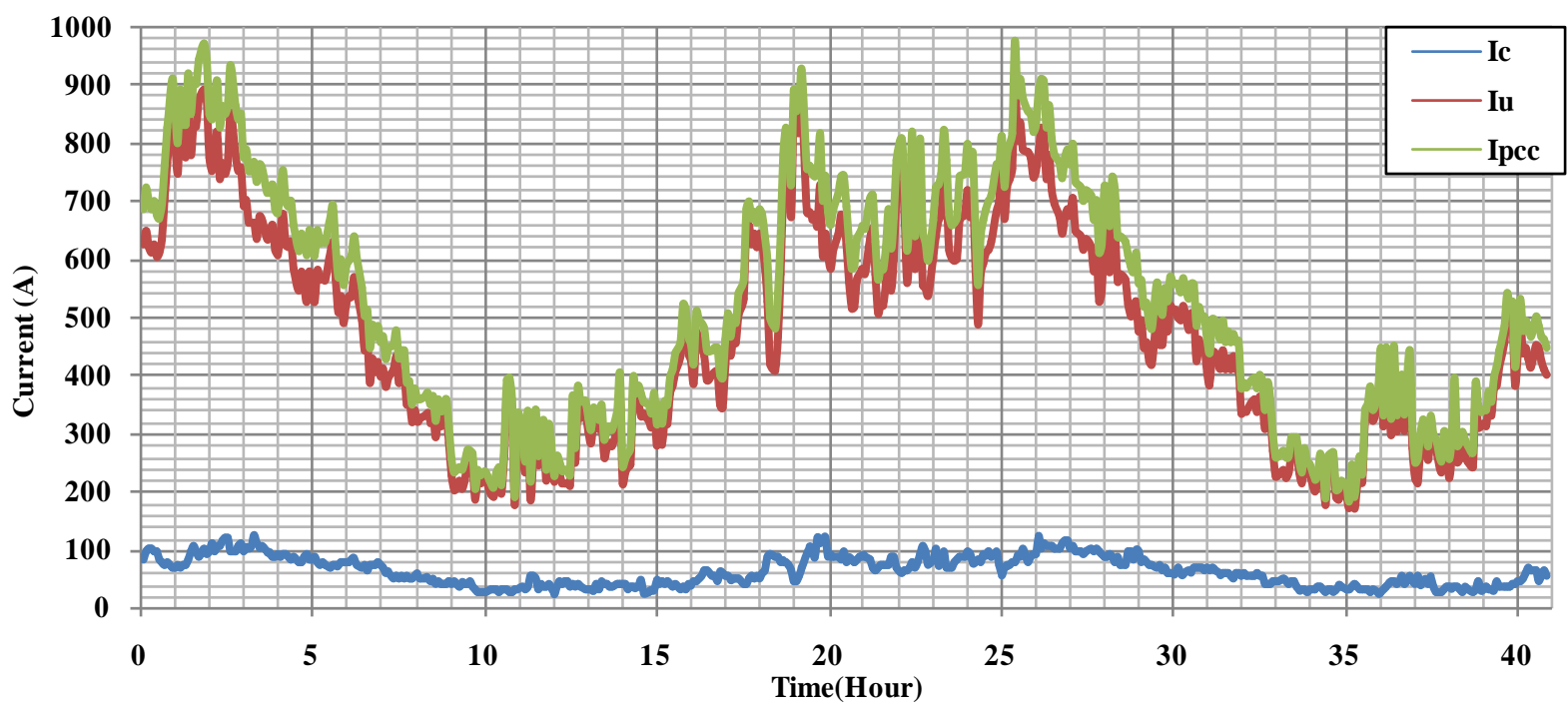

Figure 14. Customer and network current contributions to the PCC at the fundamental frequency.

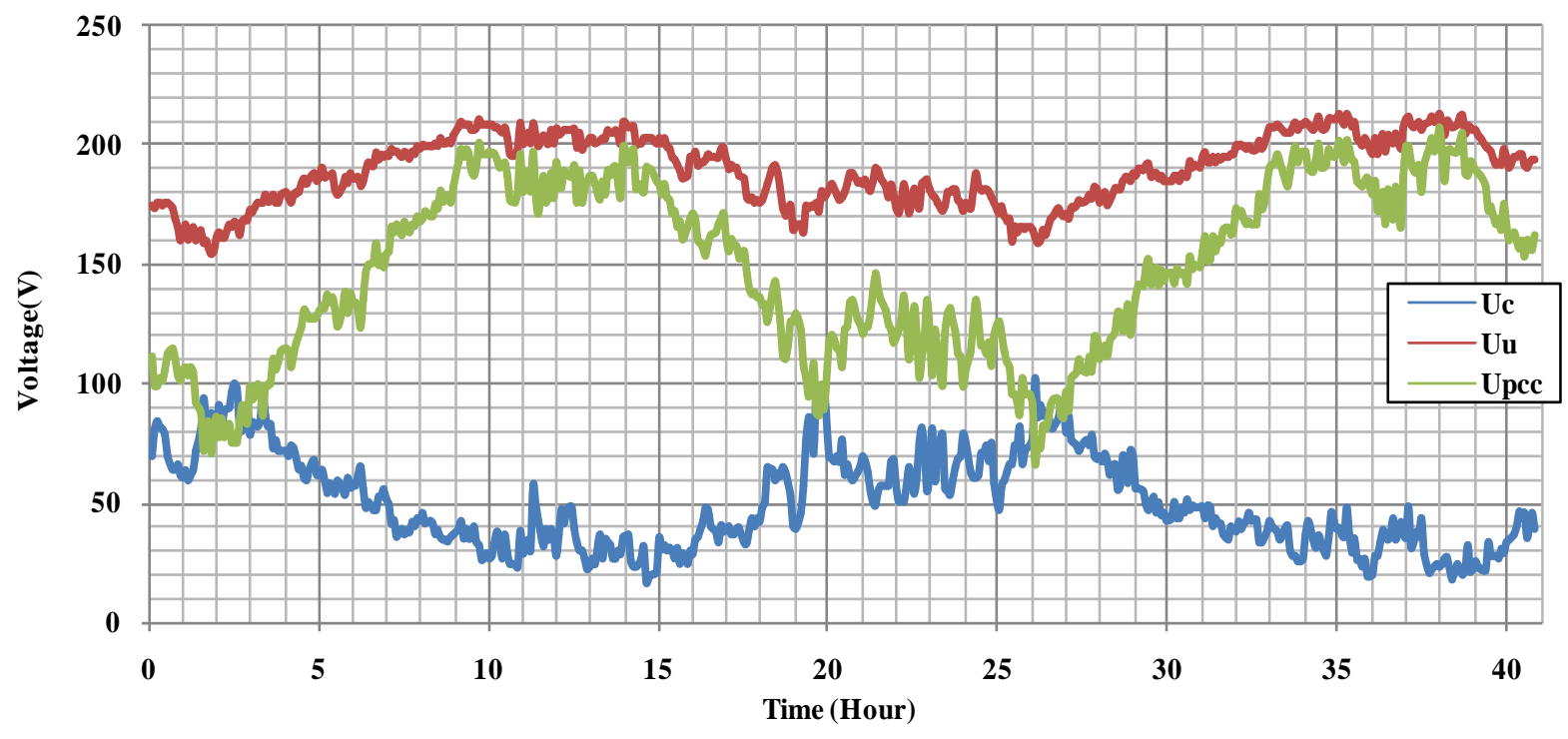

Figure 15. Customer and network voltage contributions to the PCC at the fundamental frequency. 
Harmonic voltage contribution is calculated by adapting the impedance value of the customer and network according to rank of the harmonic analysis. As a result of processing of the measured data, voltage harmonic contribution levels between the $5^{\text {th }}$ and $17^{\text {th }}$ of the customer and network to the PCC is given between Figures 17-21, respectively.

As can be seen from the referred graphs, reason for disturbance in voltage quality as well as current is results from the customer. That is, largest share in the disturbance in the waveform of the voltage at the PCC belongs to the customer. It is understood that the $5^{\text {th }}$ and $7^{\text {th }}$ voltage harmonic levels are higher than the other harmonic levels as expected from a medium power energy system.

Harmonic current contribution is calculated by adapting the impedance value of the customer and network according to rank of the harmonic analysis. As a result of processing of the measured voltage data, voltage harmonic contribution levels between the $5^{\text {th }}$ and $17^{\text {th }}$ of the customer and network to the PCC is given between Figures 22-26 respectively. As can be seen from the referred graphs, largest share in the disturbance in the waveform of the current at the PCC belongs to the customer. As shown in Figure 22 and Figure 23, $5^{\text {th }}$ and $7^{\text {th }}$ current harmonic levels are higher than the other harmonic levels as a result of the voltage harmonics.

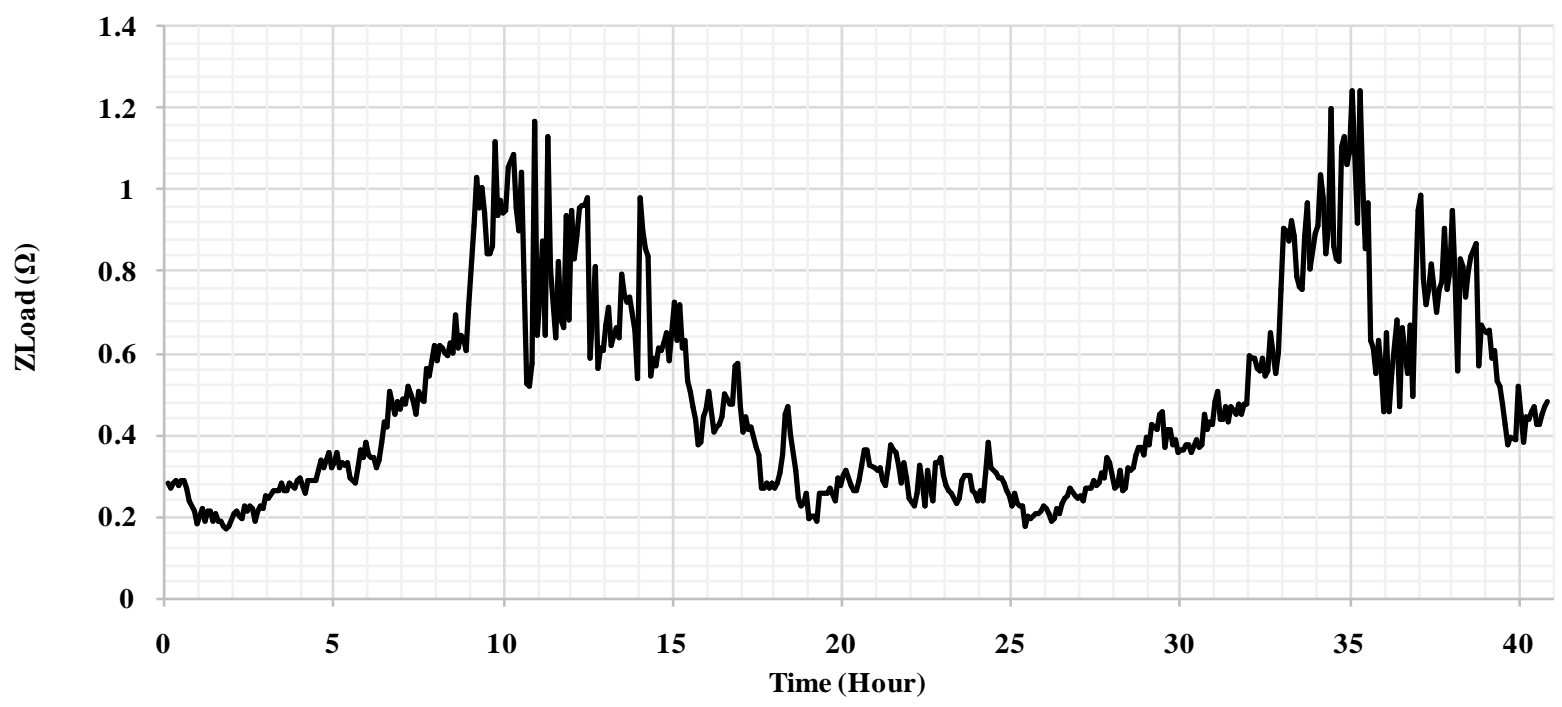

Figure 16. Magnitude of the load impedance.



Figure 17. 5th harmonics of the voltage components at the PCC. 




Figure 18. 7th harmonics of voltage components at the PCC.

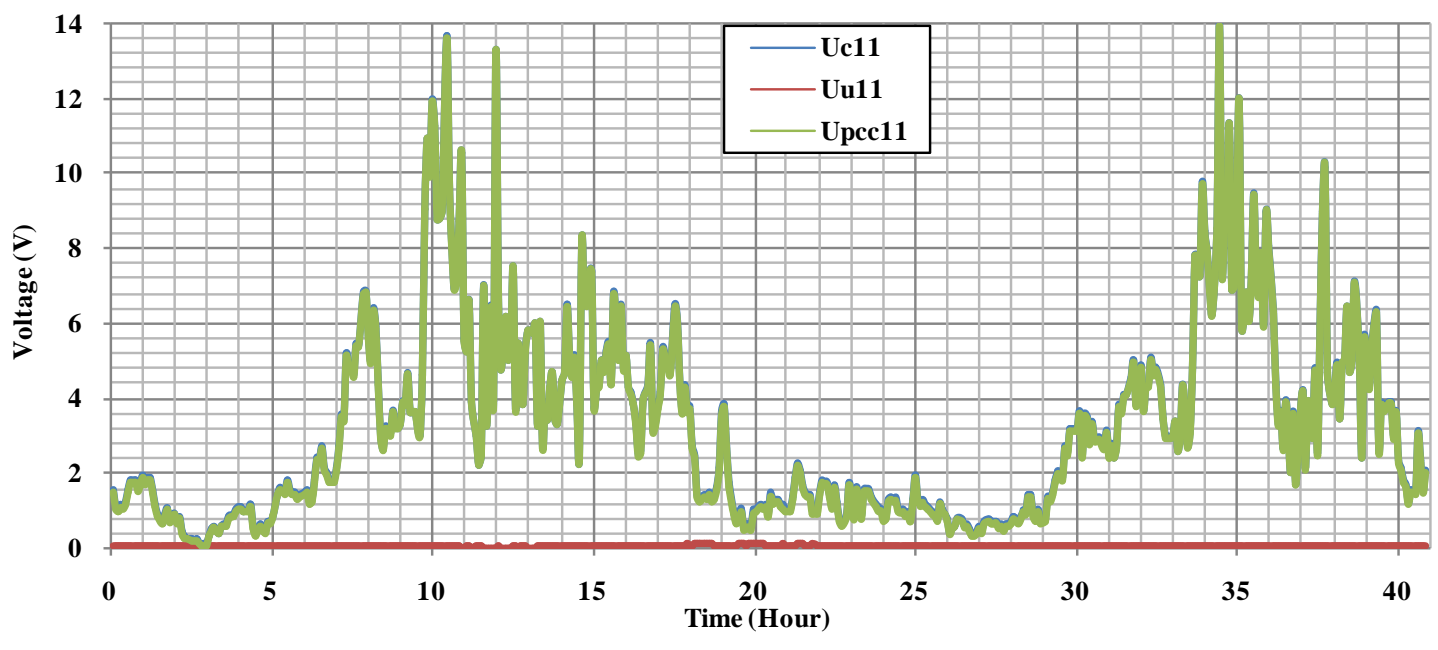

Figure 19. 11th harmonics of voltage components at the PCC.

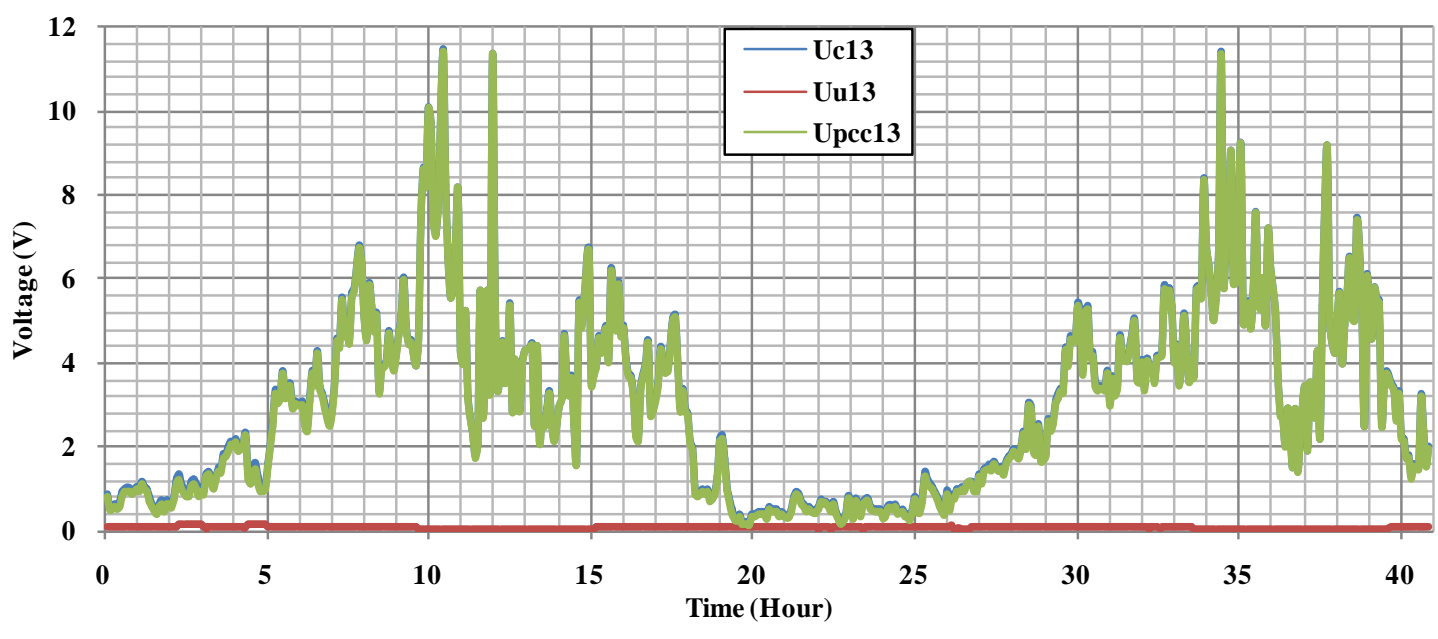

Figure 20. 13th harmonics of voltage components at the PCC. 


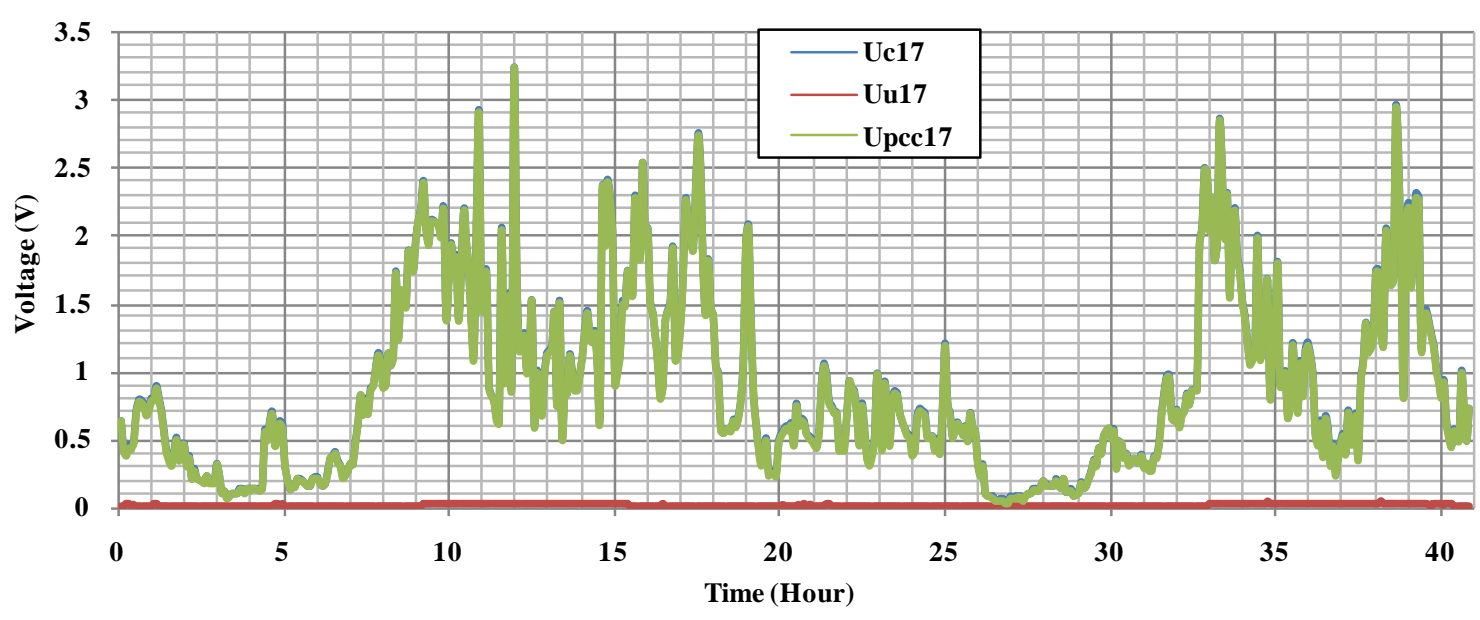

Figure 21. 17th harmonics of voltage components at the PCC.

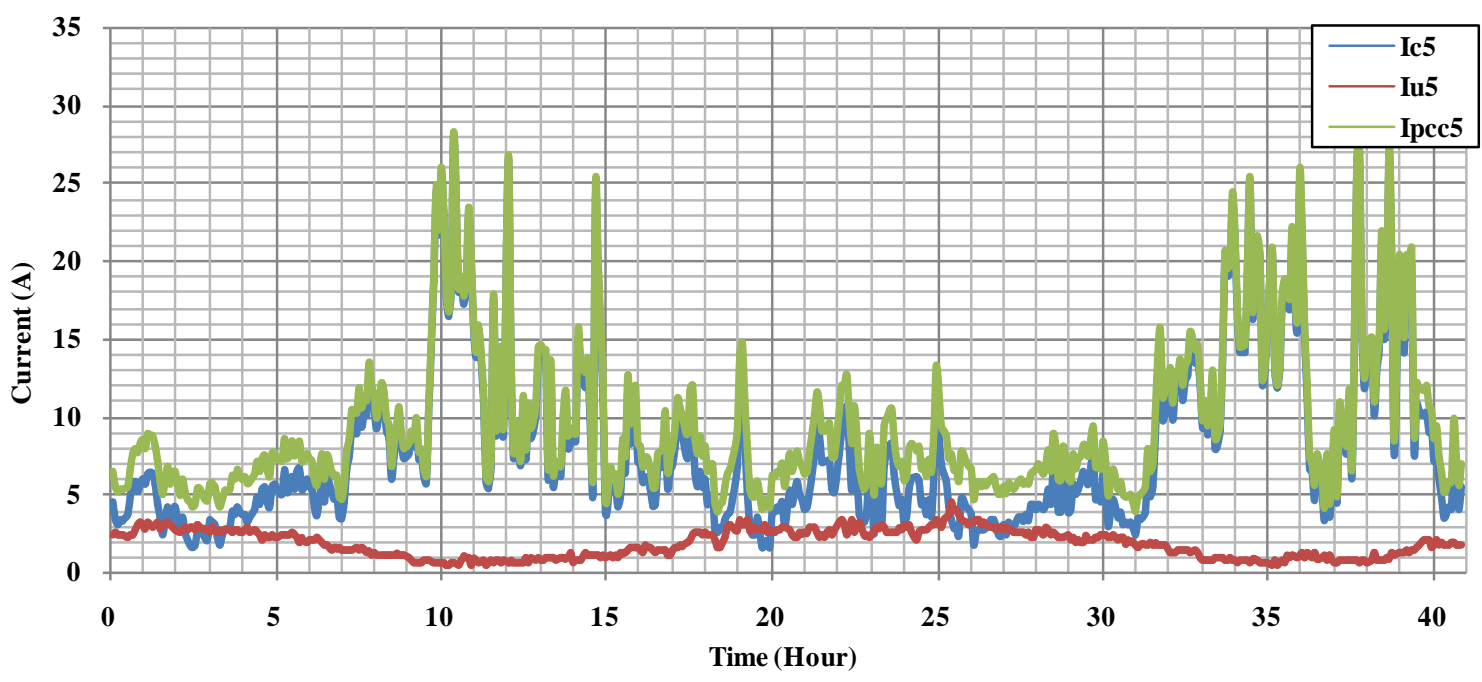

Figure 22. 5th harmonics of current components at the PCC.

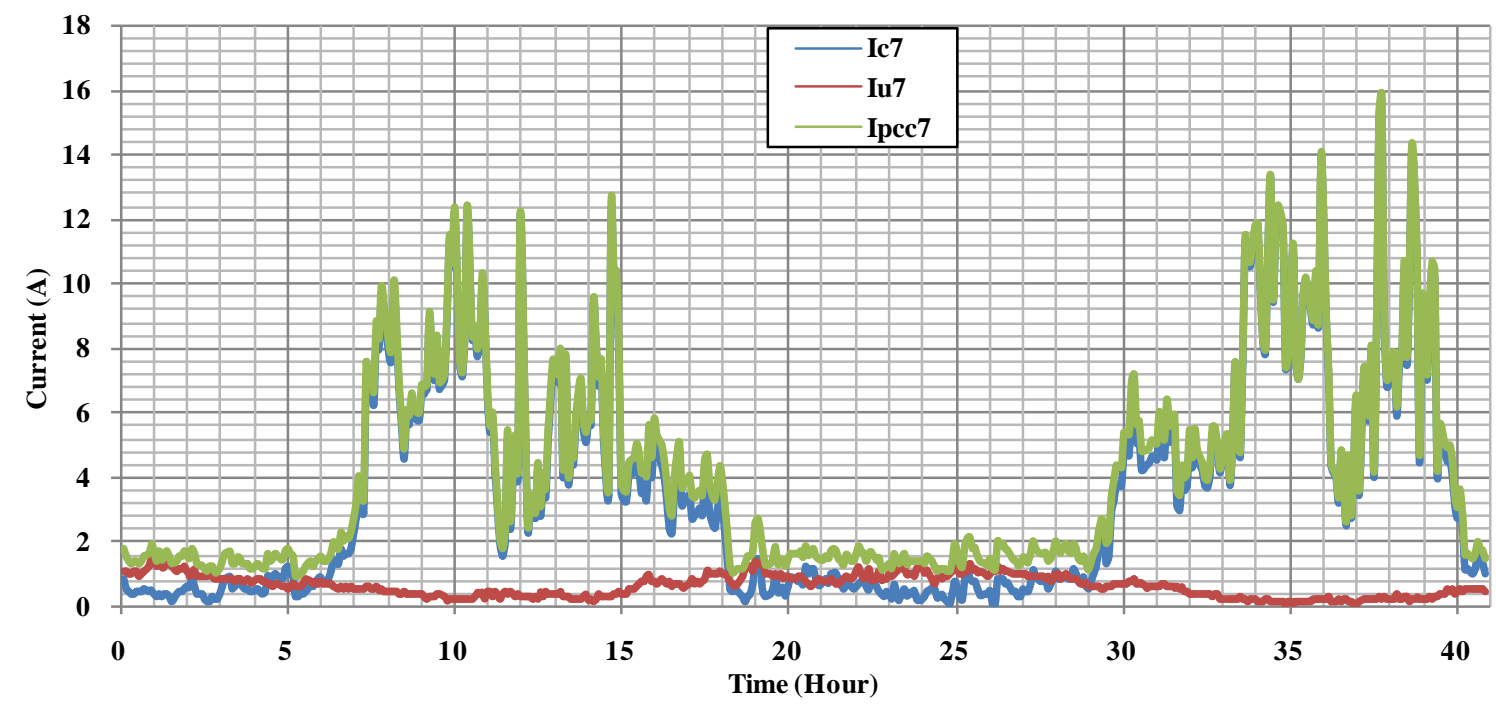

Figure 23. 7th harmonics of current components at the PCC. 


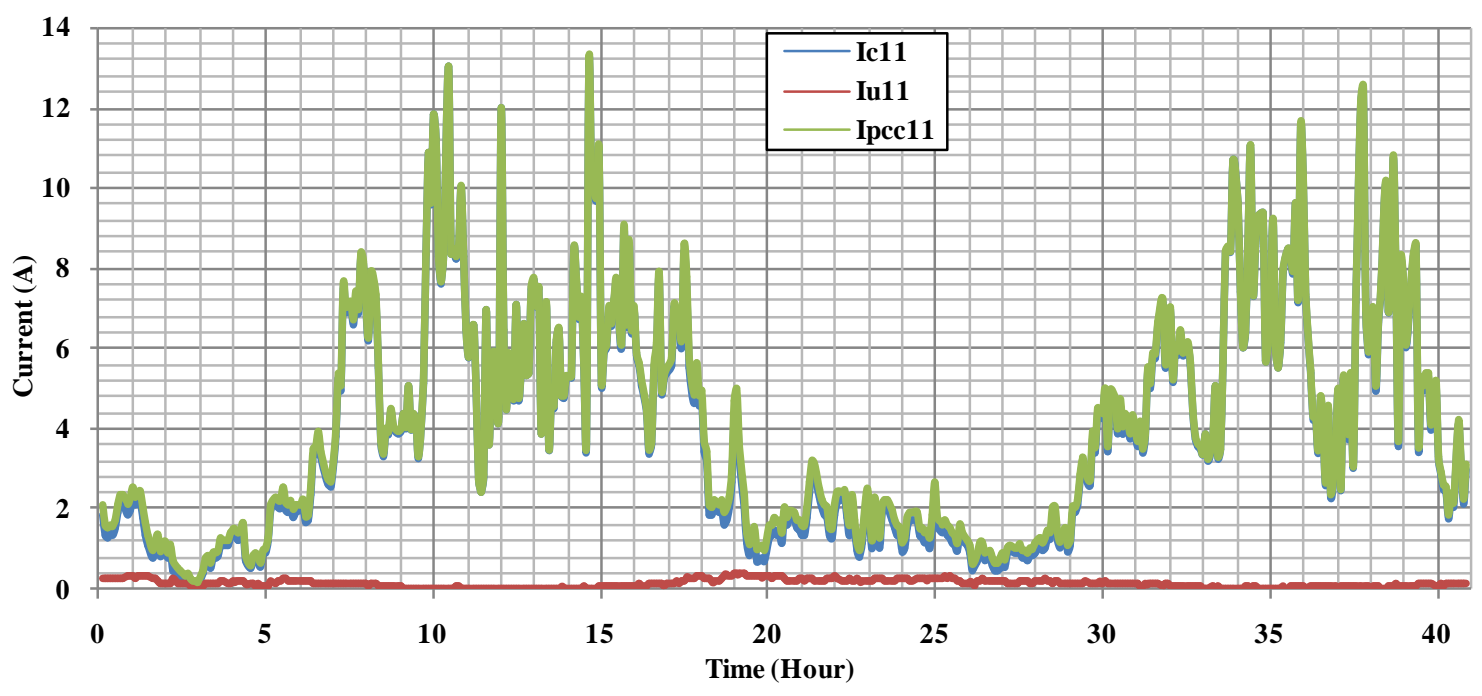

Figure 24. 11th harmonics of current components at the PCC.



Figure 25. 13th harmonics of current components at the PCC.

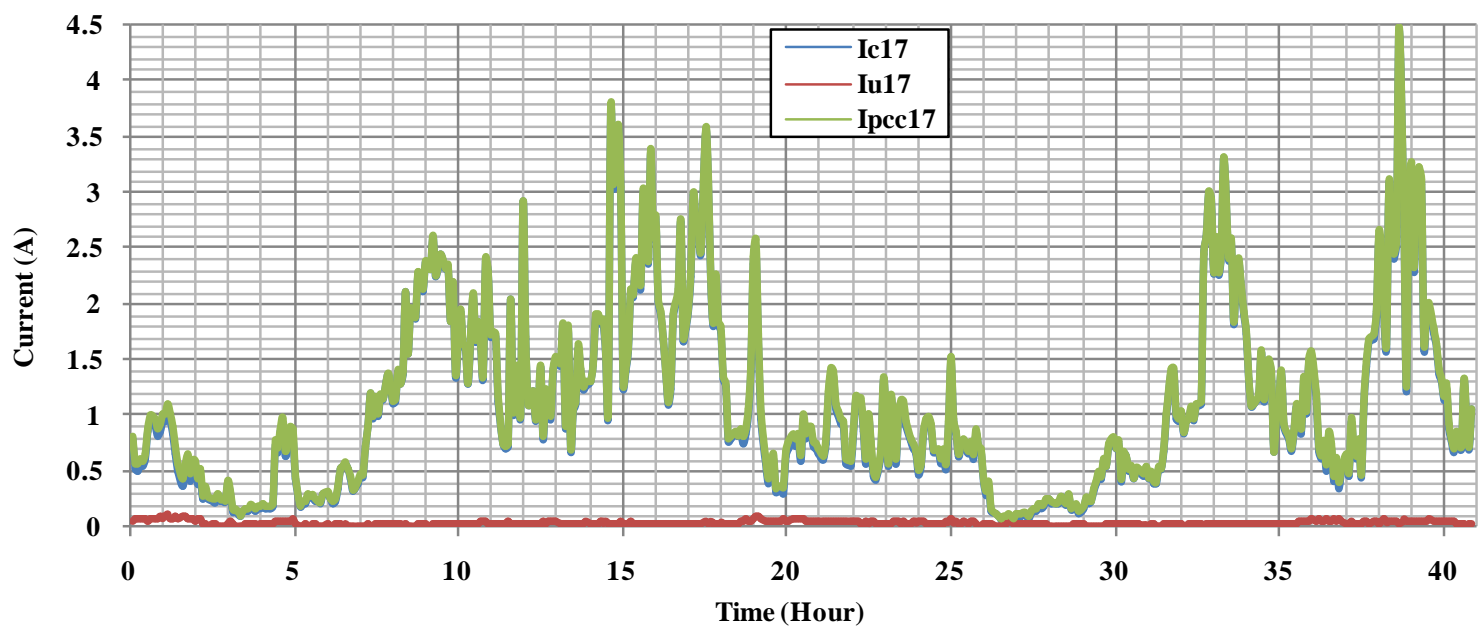

Figure 26. 17th harmonics of current components at the PCC. 
Separately calculated average (Avr.) and maximum (instantaneous value) harmonic level values of the current and voltage are given in Figure 27 and Figure 28. Actually, standards of voltage and current distortion limits are determined according to peak value of the measured current or voltage data. In order to make comparison with the max harmonic levels, average harmonic levels of the current and voltage are also presented. As seen in these figures, a large part in the responsibility for distortion at the quality of the current and voltage belongs to customer. On the other hand, the network has at least some contribution on the distortion on the waveform of the current. These values should be taken into account while calculating the reactive power consumption of the customer. As seen in the figures the $5^{\text {th }}$ and $7^{\text {th }}$ harmonic levels of the network is higher than the others. And his is very common phenomenon in the power systems. On the other hand, not only $5^{\text {th }}$ and $7^{\text {th }}$ harmonic levels of the costumer are high but also other harmonic levels are very high according to network.

Calculated voltage and current THDs according the measurement given in Table 1. Distortion at the quality of the voltage is higher than the current because of the non-sinusoidal load characteristics of the customer. As seen in the harmonic levels and THDs, there are large differences between maximum and average values of the voltage and current. In order to check the suitability of the current and voltage THDs of the network and costumer, voltage and current distortion limits are provided in Table 2 and Table 3, respectively.

Limits of allowable voltage and current distortion set by IEEE 519 [25]. IEEE 519 provides limits for harmonic current distortion in general distribution and sub-transmissJion systems based on the load compared to the system's short-circuit capacity (the ratio $I_{S C} / I_{L}$ ) as given in Table 3 . As seen in Table 1 , average voltage
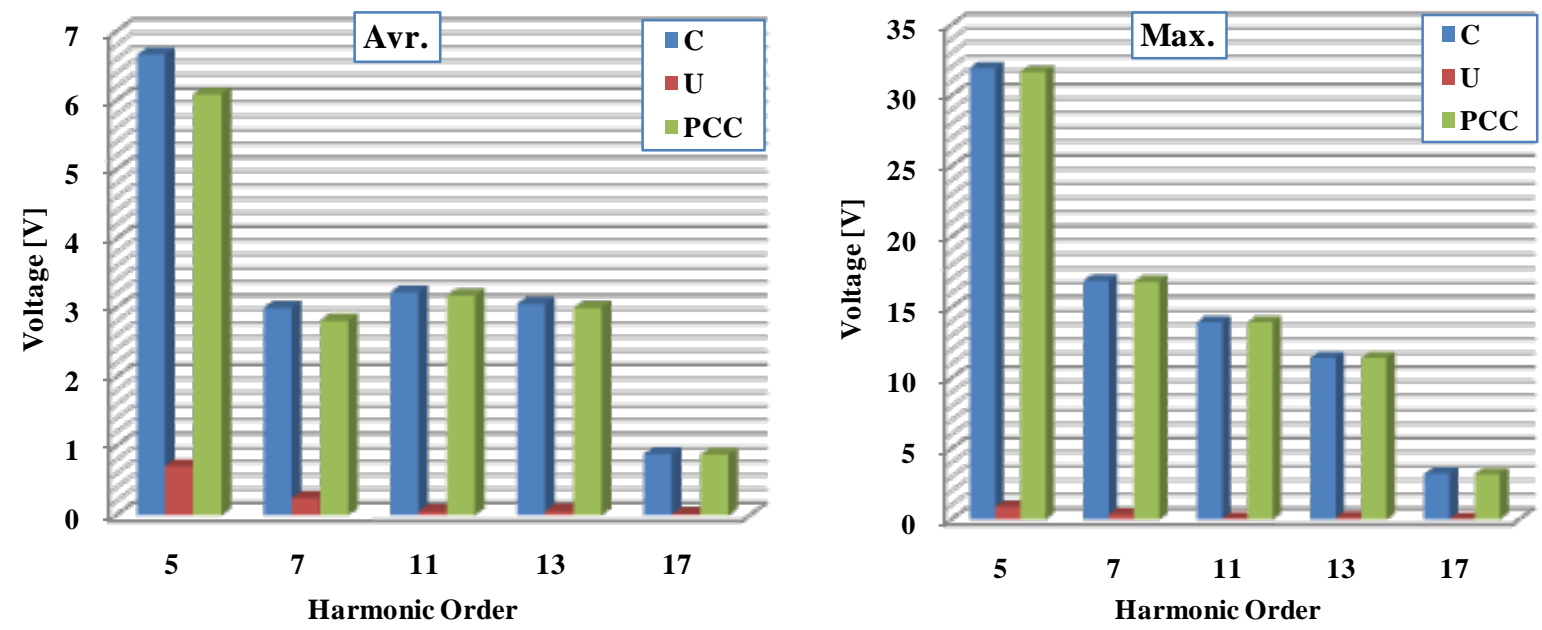

Figure 27. Harmonic level and amplitudes of the voltage components at the PCC.
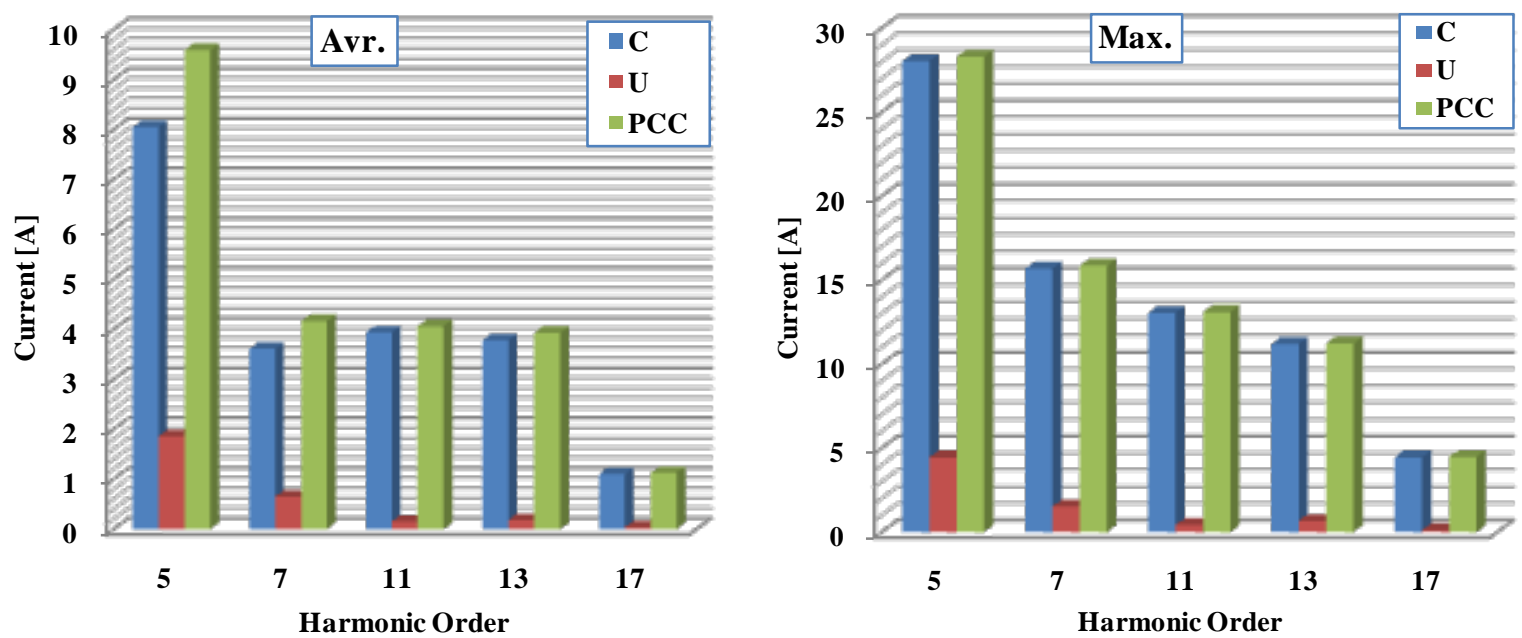

Figure 28. Harmonic level and amplitudes of current components at the PCC. 
Table 1. Current and voltage THDs.

\begin{tabular}{cccccc}
\hline & \multicolumn{3}{c}{ Current } & \multicolumn{2}{c}{ Voltage } \\
\cline { 2 - 5 } THD & Avr. & Max. & Avr. & Max. \\
\hline C & 0.165 & 0.296 & 0.172 & 0.399 \\
U & 0.005 & 0.006 & 0.004 & 0.005 \\
PCC & 0.023 & 0.038 & 0.055 & 0.195 \\
\hline
\end{tabular}

Table 2. IEEE 519 voltage distortion limits [24].

\begin{tabular}{cccc}
\hline Bus voltage at PCC & Vh, \% & THDv, \% \\
\hline $\boldsymbol{V}<\mathbf{6 9} \mathbf{~ k V}$ & 3.0 & 5.0 \\
$\mathbf{6 9} \mathbf{~ k V} \leq \boldsymbol{V}<\mathbf{1 6 1} \mathbf{~ k V}$ & 1.5 & 2.5 \\
$\boldsymbol{V}$ & $\geq \mathbf{1 6 1} \mathbf{~ k V}$ & 1.0 & 1.5 \\
\hline
\end{tabular}

Table 3. IEEE 519 current distortion limits [24].

\begin{tabular}{|c|c|c|c|c|c|c|}
\hline \multirow{2}{*}{$I_{S C} / I_{L}$} & \multicolumn{5}{|c|}{$(120 \mathrm{~V}-69 \mathrm{kV})$} & \multirow{2}{*}{\begin{tabular}{|c|}
$\mathbf{\%}$ \\
THD
\end{tabular}} \\
\hline & $H<11$ & $11 \leq h<17$ & $17 \leq h<23$ & $23 \leq h<35$ & $35 \leq h$ & \\
\hline$<\mathbf{2 0}$ & 4.0 & 2.0 & 1.5 & 0.6 & 0.3 & 5 \\
\hline $20-50$ & 7.0 & 3.5 & 2.5 & 1.0 & 0.5 & 8 \\
\hline $50-100$ & 10 & 4.5 & 4.0 & 1.5 & 0.7 & 12 \\
\hline $100-1000$ & 12 & 5.5 & 5.0 & 2.0 & 1.0 & 15 \\
\hline$>1000$ & 15 & 7.0 & 6.0 & 2.5 & 1.4 & 20 \\
\hline
\end{tabular}

THD of the customer is $17.2 \%$ while maximum voltage THD is $39.9 \%$. Both of these values exceed the voltage distortion limits as seen in Table 2.

On the other hand, neither maximum nor average voltage THD of the network exceeds the limits. Therefore, penalty sanctions should be imposed to the customer for exceeding the voltage distortion limits.

$I_{S C} / I_{L}$ of the test system is approximately 83. According to Table 3, current distortion limit for the customer is $12 \%$ while for the network is $6 \%$. Considering these current distortion limits, both of the maximum and average values of the customer exceed the limits. Therefore, another penalty sanctions should be imposed to the customer for exceeding the voltage distortion limits. Penalty rates are determined according to difference between the distortion limit and distortion of the investigated system. Considering the maximum THD values, costumer has 34.9\% more voltage and 4.5\% more current THD in the test system. Considering the average THD values, costumer has $12.2 \%$ more voltage and $4.5 \%$ more current THD in the test system. Therefore, penalty rate of the customer will be proportional with these percentages.

\section{Conclusions}

In this study, a medium voltage electrical distribution system has been investigated by using field measurement in order to determine the customer and network responsibilities. To be able to determine these responsibilities, a new algorithm based on the current vector method with the reference impedance method modified via constantly updated data has been proposed. The proposed algorithm is verified in MATLAB by processing of the measurements and the responsibilities of the customer and the network have been determined, successfully. It is understood that analysis performed with harmonic vector method using updated reference impedance is a method that is very practical and easy to apply in determining the components of network and customer at the PCC. Customer and network's individual current and voltages and also customer load impedance have been calculated 
by processing current and voltage data at the PCC with the proposed algorithm. Average and maximum value of the current and voltage THDs has been also calculated.

According to the analysis results of test system, it is determined that overall responsibilities in the current and voltage waveform distortion at the PCC only belong to the customer. Therefore, penalty sanctions should be imposed to the customer in the amount of it exceeds allowable limits. To be able to reduce to impact of the harmonics to the minimum and determine the harmonic contribution rates accurately and also determine the share of responsibility, some of the arrangements can be made as follows:

- The necessary arrangements about the harmonic contribution of the network and the customer should be performed and determined financial penalties should be applied when related limits given in the standards were exceeded.

- To take into account the average values instead of instantaneous values will be satisfy in terms of feasibility and justice while calculating the effect of the network's and the customer's harmonic distortion.

- Variable load condition should be taken into account in order to obtain more accurate results. Constantly changing load and also switching positions of the harmonic filters and compensator capacitors have been already taken into account because of the calculated load impedance by using the voltage and current data updated constantly during the measurement period.

In the future, it is planned to use the same algorithm for determining the customer and network distortion contributions in an unbalanced three phase systems. Still, billing is not made for the harmonic contributions in practice. In this regard, a digital recorder including a harmonic contribution algorithm would be useful to determine the harmonic contribution of the each customer in the allowable limits or not.

\section{Acknowledgements}

This study has been financially supported by TUBITAK with 110E134 project number. The authors would like to express their gratitude to BEDAŞ DistCo for facilitating and helping with the measurements at the substation.

\section{References}

[1] Dugan, R.C., et al. (2002) Electrical Power Systems Quality. 2nd Edition, McGraw-Hill, New York.

[2] Gul, O., Kaypmaz, A. and Tanrioven, M. (2004) A Novel Three-Phase Time Domain Load Modelling Technique Using Instantaneous Symmetrical Components. European Transactions on Electrical Power, 14, 361-375. http://dx.doi.org/10.1002/etep.28

[3] Gül, Ö. (2004) Identification of Three Phase Generic Load Model Parameters Using Field Measurements. IEEE MELECON2004, Dubrovnik.

[4] Katić, V.A., Mujović, S.V., Radulović, V.M. and Radović, J.S. (2011) The Impact of the Load Side Parameters on PC Cluster's Harmonics Emission. Advances in Electrical and Computer Engineering, 11, 103-110. http://dx.doi.org/10.4316/AECE.2011.01017

[5] Gül, Ö. and Milanovic, J. (2000) Sensitivity of Harmonic Load Model Parameters to Voltage and Current Waveforms. The International Conference on Harmonics and Quality of Power, Orlando.

[6] Qian, K., Zhou, C., Allan, M. and Yuan, Y. (2011) Effect of Load Models on Assessment of Energy Losses in Distributed Generation Planning. IJEPES, 33, 1243-1250. http://dx.doi.org/10.1016/j.ijepes.2011.04.003

[7] Stojanovic, D.P., Korunovic, L.M. and Milanovic, J.V. (2008) Dynamic Load Modelling Based on Measurements in Medium Voltage Distribution Network. EPSR, 78, 228-238. http://dx.doi.org/10.1016/j.epsr.2007.02.003

[8] Liang, X., et al. (2012) Dynamic Load Models for Industrial Facilities. IEEE Transactions on Power Systems, 27, 6980. http://dx.doi.org/10.1109/TPWRS.2011.2161781

[9] Farhoodnea, M., Mohamed, A., Shareef, H. and Zayandehroodi, H. (2012) An Enhanced Method for Contribution Assessment of Utility and Customer Harmonic Distortions in Radial and Weakly Meshed Distribution Systems. IJEPES, 43, 222-229. http://dx.doi.org/10.1016/j.ijepes.2012.05.013

[10] Thunberg, E. and Soder, L. (1999) A Norton Approach to Distribution Network Modeling for Harmonic Studies. IEEE Transactions on Power Delivery, 14, 272-277. http://dx.doi.org/10.1109/61.736738

[11] Fan, R.R., et al. (2013) A Method for Assessing Customer Harmonic Emission Level Based on the Iterative Algorithm for Least Square Estimation, Engineering, 5, 6-13. http://dx.doi.org/10.4236/eng.2013.59B002

[12] Srinivasan, K. (1996) On Separating Customer and Supply Side Harmonic Contributions. IEEE Transactions on Power Delivery, 11, 1003-1012. http://dx.doi.org/10.1109/61.489362 
[13] IEEE Std 519-1992, IEEE Recommended Pradice and Requirements for Harmonic Control in Electrical Power Systems.

[14] Xu, W. and Liu, Y. (2000) A Method for Determining Customer and Utility Harmonic Contributions at the Point of Common Coupling. IEEE Transactions on Power Delivery, 15, 804-811.

[15] Bergeron, R. and Slimani, K. (1999) A Method for the Determination of the Customer Share of the Contribution to the Level of Harmonic Voltage on an Electric Network. Proceedings of IEEE Power Engineering Society Summer Meeting, 1, 354-360.

[16] Chen, C.Y., Liu, X.L., Koval, D., Xu, W. and Tayjasanant, T. (2004) Critical Impedance Method—A New Detecting Harmonic Sources Method in Distribution Systems. IEEE Transactions on Power Delivery, 19, 288-297. http://dx.doi.org/10.1109/TPWRD.2003.820424

[17] Hamzah, N., Mohamed, A. and Hussain, A. (2005) Identification of Harmonic Source at the Point of Common Coupling Based on Voltage Indices. Jurnal Teknologi, 43, 11-32.

[18] Li, C. and Xu, W. (2002) On Defining Harmonic Contributions at the Point of Common Coupling. IEEE Power Engineering Review, 45-46.

[19] Bergeron, R. and Slimani, K. (1999) Method for an Equitable Allocation of the Cost of Harmonics in an Electrical Network. Proceedings of IEEE Power Engineering Society Summer Meeting, 1, 347-353.

[20] Cristaldi, L. and Ferrero, A. (1995) Harmonic Power Flow Analysis for the Measurement of the Electric Power Quality. IEEE Transactions on Instrumentation and Measurement, 44, 683-685. http://dx.doi.org/10.1109/19.387308

[21] Xu, W., Liu, X. and Liu, Y. (2003) An Investigation on the Validity of Power Direction Method for Harmonic Source Determination. IEEE Transactions on Power Delivery, 18, 214-219. http://dx.doi.org/10.1109/TPWRD.2002.803842

[22] Davis, E.J., Emanuel, A.E. and Pileggi, D.J. (1996) Evaluation of Single Point Measurements Method for Harmonic Pollution Cost Allocation. IEEE Transactions on Power Delivery, 11, 1003-1008.

[23] Pfajfar, T., Blažič, B. and Papič, I. (2008) Harmonic Contributions Evaluation with the Harmonic Current Vector Method. IEEE Transactions on Power Delivery, 23, 425-433. http://dx.doi.org/10.1109/TPWRD.2007.911165

[24] Varadan, S. and Makram, E.B. (1993) Generalized Load Modeling in the Presence of Hamonics and Distorion. The 25th Southeastern Symposium on System Theory (SSST'93), 124-128.

[25] ANSI/IEEE (1993) IEEE Recommended Practice and Requirements for Harmonic Control in Electrical Power Systems. Standard, ANSI/IEEE 519, IEEE, New York. 